\title{
EFECTOS DEL DEBIDO PROCESO EN LA FORMULACIÓN DE LA NIIF 13: MEDICIONES A VALOR RAZONABLE*
}

\author{
MARTHA LILIANA ARIAS BELLO* \& EDGAR EMILIO SALAZAR BAQUERO** \\ PONTIFICIA UNIVERSIDAD JAVERIANA
}

Recibido/ Received/ Recebido: 16/12/2011 - Aceptado/ Accepted/Aprovado: 06/05/2012

\begin{abstract}
Resumen
La NIIF 13 es el resultado de un extenso período de deliberación y socialización de planteamientos, orientados a definir los criterios de las mediciones a valor razonable. Esta norma surge en el proceso de convergencia adelantado entre IASB y FASB, como respuesta a una necesidad de homogeneizar las bases de esta medición, dado que su aplicación es transversal en el conjunto de Normas Internacionales de Información Financiera. Para tal fin, el debido proceso se convierte en un mecanismo para legitimar las prácticas que se esperan sean de aplicación universal. El presente documento analiza la evolución de los planteamientos conceptuales y técnicos de la NIIF 13, a partir de los desarrollos evidenciados desde el borrador de discusión de 2006. Como resultado, se evidencian los efectos derivados del debido proceso en las premisas que finalmente quedaron incorporadas en la norma definitiva
\end{abstract}

Palabras clave: valor razonable, debido proceso, borrador de discusión 2006, proyecto de norma 2009, NIIF 13.

\section{EFFECTS DUE TO THE PROCESS OF IFRS 13 FORMULATION: FAIR VALUE MEASUREMENTS}

\begin{abstract}
The IFRS 13 is the result of an ample period of debate and socialization of statements oriented to define criteria of fair value measurements. This rule arises in the convergence process performed among IASB and FASB, as a response to the necessity to homogenize this measurement bases, because its application is transversal in the group of the International Accounting Standards Board. For this purpose, the due process becomes a mechanism to legitimate practices that are expected to be of universal application. This paper analyses the evolution of conceptual and technical statements of IFRS13, since developments showed in the discussion draft of 2006. As a result, the effects from the due process in the premises, which finally were incorporated in the definitive standards, are evidenced.
\end{abstract}

Keywords: fair value, due process, discussion draft 2006, draft standard 2009, IFRS 13.

* Este documento corresponde a un producto del proyecto de investigación Identidad y Contexto Contable, denominado "Pertinencia de los estándares internacionales de valuación emitidos por el IVSC y las prácticas actuales de valuación de activos aplicadas en Colombia en la preparación de la información financiera bajo NIIF”, registrado ante la Vicerrectoría Académica de la Pontificia Universidad Javeriana Bogotá con el ID 4206.

** Profesora de planta del Departamento de Ciencias Contables de la Pontificia Universidad Javeriana Bogotá. Integrante del grupo de investigación Contexto e Integración Contable. Contadora Pública de la Pontificia Universidad Javeriana Bogotá y MBA universidad de los Andes. Correo electrónico: liliana.arias@javeriana.edu.co

*** Profesor de planta del Departamento de Ciencias Contables de la Pontificia Universidad Javeriana Bogotá. Integrante del grupo de investigación Contexto e Integración Contable. Contador Público y Especialista en Contabilidad Financiera Internacional de la Pontificia Universidad Javeriana Bogotá. Correo electrónico: edgar.salazar@javeriana.edu.co 


\title{
EFEITOS DO DEVIDO PROCESSO NA FORMULAÇÃO DA NIIF 13: MEDIÇÕES A VALOR RAZOÁVEL
}

\begin{abstract}
Resumo
A NIIF 13 é o resultado de um extenso período de deliberação e socialização de propostas, orientado a definir os critérios das medições a valor razoável. Esta norma surge no processo de convergência desenvolvido entre IASB e FASB, como resposta à necessidade de homogeneizar as bases desta medição, dado que sua aplicação é transversal no conjunto de Normas Internacionais de Informação Financeira. Para tal fim, o devido processo se converte num mecanismo para legitimar as práticas que, se esperam, sejam de aplicação universal. O presente documento analisa a evolução das propostas conceituais e técnicas da NIIF 13, a partir dos desenvolvimentos evidenciados desde o início da discussão, em 2006. Como resultado, se evidenciam os efeitos derivados do devido processo nas premissas que finalmente ficaram incorporadas na norma definitiva.
\end{abstract}

Palavras chave: valor razoável, devido processo, rascunho de discussão 2006, projeto de norma 2009, NIIF 13.

Arias, M. \& Salazar, E. (2012) Efectos del debido proceso en la formulación de la NIIF 13 - Mediciones a valor razonable. En: Revista de la Facultad de Ciencias Económicas de la Universidad Militar Nueva Granada. rev.fac.cienc.econ, XX (1)

JEL: M40, M48, M49.

\section{Introducción}

Los organismos emisores de estándares han establecido procedimientos para la expedición de sus orientaciones (Normas de Información Financiera, Normas de Aseguramiento, etc.) como una práctica que incrementa la transparencia y legitimidad del proceso. Con respecto a las Normas Internacionales de Información Financiera, vale la pena mencionar cómo el IASB (2010) tiene establecido en el prólogo, el proceso que debe llevarse a cabo para la modificación o creación de una NIIF. En particular, con respecto al proceso de emisión de la NIIF 13 - Mediciones a valor razonable, el presente documento resalta la publicación de:

- La visión preliminar del Consejo ${ }^{1}$ respecto del tema en desarrollo, junto con la invitación a comentar el documento (IASB, 2006).

- Las cartas de comentarios recibidas, junto con el análisis de tales comentarios.

- Un proyecto de norma del año 2009 y la invitación a comentar.
- Las cartas de comentarios recibidas con ocasión del proyecto de norma, junto con el análisis de tales comentarios.

- La reciente norma (NIIF 13 - 2011), junto con los fundamentos de las conclusiones.

Todos estos documentos, disponibles en la página del IASB (y/o del FASB), permiten a los interesados conocer el desarrollo del proceso y tomar posiciones mucho más argumentadas. Con fundamento en lo anterior, el presente escrito pretende contribuir a un mejor entendimiento de la NIIF 13 (IASB, 2011a) a través del análisis del debido proceso llevado a cabo por IASB (2011b) y sus resultados.

En el primer apartado se presenta un breve recorrido histórico por las discusiones generadas alrededor del concepto de valor razonable, continuando con la descripción de los fundamentos que hicieron que el tema de valor razonable fuera abordado como un proyecto de convergencia entre IASB y FASB. Finalizando el apartado introductorio, se relata una breve reseña histórica sobre los principales

1 Aunque no es obligatoria, se ha venido realizando en los últimos proyectos. 
momentos que se presentaron en la elaboración de la NIIF 13.

Posteriormente, el documento desarrolla cada una de las secciones de la NIIF 13 presentando, en primer lugar un detalle de los requerimientos de la sección de la NIIF, para luego presentar un análisis histórico de lo expuesto en los documentos del debido proceso.

A modo de conclusión y contrastando las propuestas iniciales con los requerimientos finales contenidos en la NIIF 13, el documento categoriza, mediante tres escenarios, los efectos que tuvo el debido proceso.

\section{Valor razonable, posturas y antecedentes}

\subsection{Valor razonable: ¿Un concepto nuevo?}

Diferentes autores sostienen que el uso de las mediciones a valor razonable es casi tan antiguo como las prácticas contables contemporáneas. Por ejemplo, Solomon (1936) encuentra una muestra representativa de entidades en los Estados Unidos que entre el período 1925 y 1934 utilizan valores actuales para presentar algunos de sus activos.

Sin embargo, la Gran Depresión de 1929 - 1930, fue uno de los momentos cruciales de la historia, debido a que el uso de valores de mercado pasó a un segundo plano, principalmente por la tendencia de incorporar prácticas contables mucho más conservadoras en los reportes financieros. En esta línea, Zeff (2007) realiza un recorrido histórico por el período 19351970, demostrando el papel predominante de la Security and Exchange Commission SEC en la de la contabilidad a costo histórico durante este período.

En Europa, Georgiou (2008) realizan un recorrido por la normatividad contable, particularmente en el Reino Unido, concluyendo que la contabilidad del valor razonable no es una práctica nueva en el mundo. En el período de 1800 - 1970 se encontraron evidencias de regulaciones que requerían la presentación de reportes financieros basados en medidas de mercado en la fecha del reporte. Jacques (2004), también expone que el uso de valores de mercado fue dominante en Francia durante el siglo XIX, para la valuación de partidas del estado de situación financiera.

A pesar de todo lo anterior, es a partir de los años 70, la época de la nueva regulación contable en el mundo en donde se incorpora formalmente el concepto de valor razonable. El nacimiento del IASB, FASB y de otros organismos reguladores como el Accounting Standards Committee (ASC) en el Reino Unido generó una gran cantidad de nuevas normas contables, en las cuales empezó a ser introducido el concepto de valor razonable. Este proceso, ha intensificado el debate sobre la legitimidad del valor razonable como criterio de medición.

\subsection{Posturas sobre la aplicación del valor razonable}

A pesar de que los actuales emisores de estándares apoyan el uso de este criterio, la discusión no parece estar resuelta. Paradójicamente, como se mencionó anteriormente, en el período 1934- 1970, la SEC fue particularmente inflexible al defender el principio de la contabilidad a costo histórico, al tiempo que recibía críticas por su posición. Robert E. Healy, presidente de la SEC en los finales de los 30, citado por Zeff (2007, 2), expresó:

'the purpose of bookkeeping and accounting was to make a historical record of events...' (...), '...I think the purpose of accounting is to account-not to present opinions of value'

Se concluye, entonces, que tanto las primeras aproximaciones al concepto, como las discusiones sobre la relevancia del valor razonable han persistido históricamente, no obstante algunos han cambiado su posición al respecto.

Posteriormente, las recientes crisis financieras han sido elementos detonantes para discusiones mucho más profundas sobre el concepto de valor razonable. Con ocasión de la crisis de los mercados financieros en los Estados Unidos durante los años 2007 y 2008 , se escucharon diversas voces que consideraban que la contabilidad a valor razonable fue uno de los causantes de la inestabilidad de los mercados. 
A raíz de esto en 2008 , la SEC condujo un estudio sobre valor razonable que le fue encargado por el Emergency Economic Stabilization Act of 2008, particularmente, sobre el tema denominado mark-to mark accounting (Valorar al mercado). A juicio de los autores del presente artículo, dos de las conclusiones centrales del estudio son:

"The Staff's research on this issue reflects that, based on these sources, investors generally support measurements at fair value as providing the most transparent financial reporting of an investment, thereby facilitating better investment decision-making and more efficient capital allocation amongst firms."

\section{"... bank failures in the U.S. appeared to be the result of growing probable credit losses, concerns about asset quality, and, in certain cases, eroding lender and investor confi- dence. For the failed banks that did recog- nize sizable fair value losses, it does not ap- pear that the reporting of these losses was the reason the bank failed" (SEC, 2008, 5).}

Las recomendaciones que en su momento realizó el estudio pueden resumirse en:

- La contabilidad a valor razonable debe ser mejorada pero no debe ser suspendida.

- Deben mejorarse los requerimientos para medir el deterioro de los activos.

- Deben desarrollarse guías adicionales que mejoren y fomenten el uso del criterio en los preparadores de la información.

- Debe considerarse la necesidad de simplificar la contabilidad de los activos financieros.

Como se observa y aunque pareciese contradictorio, la crisis de crédito en Estados Unidos (que terminó siendo una crisis global) resultó incrementando el apoyo a la contabilidad del valor razonable, no solo en Norteamérica sino a nivel internacional. Pruebas de lo anterior, son las declaraciones varios organismos internacionales al respecto.

Novoa et al. $(2009,5)$ presentan en el informe publicado por el Fondo Monetario Internacional, la si- guiente conclusión con respecto a la contabilidad a valor razonable (FVA):

"The paper finds that, despite concerns about volatility and measurement difficulties, FVA is the appropriate direction forward and can provide a measure that best reflects a financial institution's current financial condition."

La declaración del G-20 en su reunión de abril de 2009, contiene (Subrayado fuera del texto):

"We have agreed that the accounting standard setters should improve standards for the valuation of financial instruments based on their liquidity and investors' holding horizons, while reaffirming the framework of fair value accounting" (G-20, 9).

A nivel iberoamericano, en países como Argentina, Chile y México, se ha incorporado el concepto de valor razonable mediante un proceso, bien sea de adopción o de convergencia hacia las NIIF. En el marco conceptual definido en México citado por Patiño $(2009,71)$ se enuncia: "El principio de valor histórico original se sustituye por el postulado de valuación, el cual establece la forma de cuantificar las operaciones que lleva a cabo una entidad y otros eventos que la afectan".

En el caso de Chile, la adopción de estos estándares impone cambios en la valorización a valor razonable de los activos y pasivos de las compañías. Esto significa que éstos deberán ser medidos de acuerdo a lo que un comprador bien informado pagaría a un vendedor bien informado por un bien o servicio determinado, método de valorización que dista mucho del costo histórico que actualmente se utiliza en Chile, y que hará que los informes queden más expuestos a las volatilidades del mercado (Zuñiga, Pacheco \& Díaz, 2009, 81).

En este mismo sentido, Navarro \& Pérez (2007) en su reflexión sobre la repercusión del valor razonable en la utilidad de los estados financieros en España, exponen que en comparación con el coste histórico, el valor razonable generaría información financie- 
ra bastante menos objetiva y verificable, lo que, en buena lógica, aumentaría la complejidad y el esfuerzo derivado de los trabajos de auditoría. Paralelamente, en la cuantificación de las estimaciones del valor razonable, los principales problemas de viabilidad tienen origen, sobre todo, en los elevados costes de las mismas, en la posible inexistencia de métodos de valoración generalmente aceptados y en las dificultades del personal de las empresas para obtener su cuantificación.

En la misma línea, Castellanos (2009) explica diferentes desventajas del uso del valor razonable en los estados financieros. Quienes se oponen al concepto argumentan que éste menoscaba la fiabilidad de la información debido a que las valoraciones (cuando no existen mercados activos) tienden a ser altamente subjetivas y, por lo tanto, existe un incremento significativo en el nivel de riesgo en el proceso de toma de decisiones de los usuarios. Asimismo, expone las ventajas de este criterio de medición, argumentando que las mediciones de valor razonable mejoran la relevancia de la información financiera porque presentan las condiciones actuales sobre sucesos o transacciones.

Otros estudios analizan la forma en que se introduce el concepto de valor razonable en las normas contables. Por ejemplo, Cairns et al. (2011) analizan los impactos de las mediciones voluntarias y obligatorias de valor razonable en las NIIF. En algunas compañías en el Reino Unido y Australia, se encontró evidencia de que las mediciones obligatorias de valor razonable mejoran la comparabilidad de la información financiera. Sin embargo, las mediciones opcionales a valor razonable tienden a mermar la comparabilidad, particularmente en temas tan relevantes como la NIC 39. Esto se explica porque las opciones de políticas contables sobre medición permitirían a unas entidades utilizar criterios distintos como el costo o el costo amortizado, mientras que otras usarían el valor razonable.

Silva \& Azua $(2006,13)$ también encuentran elementos claves de análisis sobre la introducción del concepto de valor razonable. En su trabajo, concluyen que el valor razonable supone: la eliminación del concepto prudencial de las normas contables, la utilización del modelo de mantenimiento de capital operativo, la presentación separada de las ganancias y pérdidas de valoración realizadas de las no realizadas, un incremento en las revelaciones hacia los usuarios, y mayores costos y complejidad en el proceso contable.

Concluyendo sobre lo anterior, no existe consenso frente a la utilización de las mediciones a valor razonable dado que se encuentran argumentos válidos en cada una de las posiciones. Para los autores del presente documento ésta forma de medición es de utilidad para los usuarios de la información al reflejar de mejor manera las condiciones presentes sobre la posición financiera y el desempeño de las entidades, a pesar de las dificultades en su estimación.

Al respecto, vale la pena resaltar que las actuales Normas Internacionales de Información Financiera emitidas por el IASB, mantienen un modelo de valoración mixto, que incorpora mediciones a valor razonable, a costo histórico, a costo amortizado, entre otros. En el corto plazo, tampoco parece que los estándares se dirijan hacia el uso exclusivo del valor razonable. A manera de ejemplo, puede leerse en varios de los proyectos actuales de IASB. En el borrador de discusión sobre actividades extractivas, publicado para comentarios por IASB $(2010,100)$, se propone la medición del activo reconocido por su costo histórico, a pesar de que la medición de este activo por su valor razonable fue estudiada:

"Fair value conceptually provides relevant information. However, owing to the subjectivity and degree of estimation involved, users do not view entity-prepared current values as being representationally faithful, and therefore they would make limited use of them (...) The project team thinks that measuring these assets at current value would not meet a cost-benefit test."

En el proyecto conjunto de IASB y FASB sobre arrendamientos, también por la complejidad asociada a la determinación del valor razonable, se decidió que el activo consistente en el derecho a usar el bien arrendado se medirá inicialmente al costo. 
La reciente NIIF 9 requiere la medición posterior de los activos financieros al valor razonable o al costo amortizado. En los fundamentos de las conclusiones puede leerse:

“... el Consejo decidió que medir todos los activos financieros a valor razonable no es el enfoque más adecuado para mejorar la información financiera para los instrumentos financieros (...) El Consejo destacó que ambos métodos de medición pueden proporcionar información útil a los usuarios de los estados financieros para tipos particulares de activos financieros en circunstancias concretas."

En términos de relevancia, el valor razonable es visto como una de las mejores alternativas de medición porque representa las condiciones existentes del mercado. Sin embargo, en circunstancias particulares, algunas formas de medición distintas al valor razonable pueden presentar información valiosa sobre los activos o los pasivos. De igual forma, la restricción del costo planteada en el marco conceptual, es una justificación para optar por el uso de mediciones distintas al valor razonable.

\subsection{Proyecto de convergencia IASB - FASB}

Los escándalos corporativos en los Estados Unidos al comienzo de éste siglo crearon una fuerte presión para mejorar los requerimientos existentes sobre Gobierno Corporativo y Reportes Financieros. Como consecuencia de esto, el Congreso de los Estados Unidos aprobó la Ley Sarbanes-Oxley $(2002,25)$ que además de requerir a la SEC la realización de un estudio sobre la adopción en los Estados Unidos de un sistema de normas sobre reportes financieros basado en principios, se pronunció en favor de la convergencia, manifestando:

“... considers, in adopting accounting principles, the need to keep standards current in order to reflect changes in the business environment, the extent to which international convergence on high quality accounting standards is necessary or appropriate in the public interest and for the protection of investors"
Las reacciones no se hicieron esperar debido a que en septiembre de 2002, IASB y FASB firmaron el acuerdo de Norwalk comprometiéndose a trabajar juntos para lograr el objetivo de conseguir un único conjunto de estándares contables de alta calidad (IASB \& FASB, 2002).

Desde su creación en 1973, IASB (anteriormente IASC) ha venido trabajando para lograr que sus estándares se conviertan en un único conjunto global de estándares contables sobre Reportes Financieros. Por eso, ha buscado el consenso y la participación de los reguladores contables nacionales de todo el mundo para trabajar juntos en esa dirección. El acuerdo con el FASB fue uno de los hitos más importantes en la historia del IASB, clarificando el proceso de la convergencia global de los estándares contables.

Años más tarde, en febrero de 2006, IASB y FASB suscribieron un nuevo documento titulado "A Roadmap for Convergence between IFRSs and US GAAP-2006-2008 Memorandum of Understanding between the FASB and the IASB", reafirmando su compromiso de trabajar juntos en el mejoramiento de los estándares contables. Dentro de este documento, los dos Consejos propusieron eliminar las principales diferencias de los estándares en temas claves dentro de los cuales se incluyó el valor razonable (IASB \& FASB, 2006).

La principal razón de incluir el tema de valor razonable en el memorando de entendimiento es que los dos Consejos encontraron que dentro de cada uno de los conjuntos de estándares sobre reportes financieros (NIIF - US-GAAP) se encontraban diferentes definiciones sobre valor razonable, además de guías distintas sobre su aplicación, que se encontraban dispersas dentro de diferentes estándares. Esto creaba inconsistencias entre los estándares que añadían complejidad y reducían la calidad y la comparabilidad de los reportes financieros. Por tal razón, se consideró importante unificar las definiciones y los requerimientos sobre la medición a valor razonable dentro del proceso de convergencia, lo que redundaría en la simplificación y por supuesto, en una mejora a los reportes financieros de las entidades que apliquen las IFRS o los US-GAAP. 


\subsection{Antecedentes de la NIIF 13}

La NIIF 13 sobre mediciones a valor razonable se sustenta en los antecedentes que condujeron a la definición de esas directrices (Tabla 1):

Tabla 1. Antecedentes de la NIIF $13^{2}$

\begin{tabular}{|c|c|c|}
\hline Año & País & Uso \\
\hline 2003 & $\begin{array}{l}\text { FASB en junio inició el proyecto } \\
\text { sobre mediciones a valor razo- } \\
\text { nable }\end{array}$ & \\
\hline 2005 & $\begin{array}{l}\text { FASB llevaba a cabo delibera- } \\
\text { ciones sobre los planteamientos } \\
\text { del proyecto }\end{array}$ & $\begin{array}{l}\text { IASB en junio inició el pro- } \\
\text { yecto sobre mediciones a } \\
\text { valor razonable }\end{array}$ \\
\hline 2006 & $\begin{array}{l}\text { FASB en septiembre emitió el } \\
\text { SFAS } 157 \text { (tema } 820 \text { ) - estable- } \\
\text { ció un marco para las medicio- } \\
\text { nes a valor razonable y las reve- } \\
\text { laciones sobre esta medición }\end{array}$ & $\begin{array}{l}\text { IASB en junio inició el pro- } \\
\text { yecto sobre mediciones a } \\
\text { valor razonable }\end{array}$ \\
\hline 2007 & & $\begin{array}{l}\text { IASB inicia en septiembre las } \\
\text { deliberaciones para el desa- } \\
\text { rrollo del proyecto de norma } \\
\text { sobre mediciones al valor } \\
\text { razonable }\end{array}$ \\
\hline \multirow[t]{2}{*}{2009} & & $\begin{array}{l}\text { IASB publica en mayo el } \\
\text { proyecto de norma en el que } \\
\text { propone una definición de } \\
\text { valor razonable, un marco } \\
\text { para medir el valor razonable } \\
\text { y revelaciones sobre las me- } \\
\text { diciones del valor razonable. } \\
\text { Se recibieron } 160 \text { cartas de } \\
\text { comentarios en respuesta a } \\
\text { la propuesta. El factor común } \\
\text { de los comentarios recibidos } \\
\text { fue la solicitud a IASB y FASB } \\
\text { de trabajr conjuntamente en } \\
\text { el desarrollo común de estos } \\
\text { criterios, dado que si bien el } \\
\text { IASB tomó como referencia el } \\
\text { SFAS } 157 \text { existían diferencias } \\
\text { en criterios }\end{array}$ \\
\hline & \multicolumn{2}{|c|}{$\begin{array}{l}\text { Como respuesta a la solicitud de un trabajo conjunto, en octubre } \\
\text { se realiza una reunión entre los dos organismos y se proyecta } \\
\text { un trabajo mancomunado para mejorar la comparabilidad de los } \\
\text { estados financieros preparados de acuerdo con las NIIF y los US- } \\
\text { GAAP. En consecuencia, acordaron considerar los comentarios } \\
\text { recibidos sobre el proyecto de IASB y proponer enmiendas a los } \\
\text { US-GAAP, si es necesario. }\end{array}$} \\
\hline 2010 & $\begin{array}{l}\text { En enero se inicia formalmente e } \\
\text { organismos, el cual se centra en } \\
\text { diferencias entre los requisitos de } \\
\text { el proyecto de exposición de IAS } \\
\text { dos por IASB al proyecto de disc }\end{array}$ & $\begin{array}{l}\text { trabajo conjunto entre los dos } \\
\text { os siguientes aspectos: a ) Las } \\
\text { I SFAS } 157 \text { y los expuestos en } \\
\text { s. b) ) Los comentarios recibi- } \\
\text { sión. }\end{array}$ \\
\hline
\end{tabular}

\section{Análisis de la NIIF 13}

A continuación se presentan cada una de las secciones de la NIIF 13 junto con las posiciones y decisiones generadas por los documentos del debido proceso.

\subsection{Alcance}

\subsubsection{Descripción de la sección}

La norma es aplicable para la gran mayoría de las mediciones a valor razonable requeridas o permitidas por las NIIF. Sin embargo, existen excepciones de su aplicación para algunas mediciones a valor razonable:

- Pagos basados en acciones descritos en la NIIF 2

- Contratos de arrendamiento dentro del alcance de la NIC 17

- Mediciones que tienen algunas similitudes con el valor razonable pero no son mediciones a valor razonable (valor en uso, valor neto realizable).

También se excluyen del alcance de la NIIF 13 las revelaciones requeridas acerca de:

- Activos e inversiones de planes de beneficios medidos al valor razonable de acuerdo con la NIC 19 y la NIC 26.

- Activos para los cuales su importe recuperable es el valor razonable menos costos de disposición (NIC 36).

\subsubsection{Efectos del debido proceso}

El borrador de discusión (IASB, 2006) contenía la visión preliminar de que el nuevo estándar debería contener la única fuente de orientación para las mediciones a valor razonable requeridas por las NIIF. Por lo tanto no contenía ninguna exclusión en el alcance y se propuso que la NIIF 13 fuera aplicable en todas las mediciones de valor razonable requeridas o permitidas por las NIIF. Esto suponía la modificación de todas las normas que incluían guías acerca de la determinación o de la información a revelar del valor razonable.

Posteriormente, el proyecto de norma concluyó que en tres circunstancias el término de valor razonable

\footnotetext{
2 Fuente: Bases para conclusiones NIIF 13 y Accounting Standards Update 2011-04 (FASB, 2011)
} 
era usado en una forma inconsistente con la definición propuesta de valor razonable. Por estas razones, el proyecto de norma propuso excluir del alcance de la nueva NIIF, el párrafo 49 de la NIC 39. También se propuso modificar el término valor razonable en la NIIF 2 (para la medición de pagos basados en acciones) y en la NIIF 3 (para la medición de derechos readquiridos en una combinación de negocios).

En la NIIF 13, finalmente se excluyen del alcance:

- Pagos basados en acciones descritos en la NIIF 2.

- Contratos de arrendamiento dentro del alcance de la NIC 17.

- Mediciones que tienen algunas similitudes con el valor razonable pero no son mediciones a valor razonable (valor en uso, valor neto realizable).

También determinó que no se requerirían las revelaciones de la NIIF 13 para:

- Activos e inversiones de planes de beneficios medidos al valor razonable de acuerdo con la NIC 19 y la NIC 26.

- Activos para los cuales su importe recuperable es el valor razonable menos costos de disposición (IAS 36).

Con respecto a las exclusiones de medición, el Consejo encontró que algunas mediciones de la NIIF 2 eran consistentes con la definición de valor razonable mientras que otras no, por lo cual se requeriría la incorporación de una nueva base de valor en la NIIF 2, lo que podría traer cambios no deseados en la práctica. Por tanto, decidió excluir las mediciones de la NIIF 2 del alcance de la NIIF 13. También reflexionó que la aplicación de la NIIF 13 a los arrendamientos podría cambiar la clasificación de algunos arrendamientos y también la forma de contabilizar las transacciones de retro-arriendo. Consecuentemente con lo anterior y considerando que existe un proyecto para modificar la NIC 17, el Consejo decidió no aplicar los requerimientos de valor razonable de la NIIF 13 a los contratos de arrendamientos bajo el alcance de la NIC 17. Con respecto a la NIIF 3, el consejo notó que en la NIIF 3 era claro que la medición de derechos readquiridos era una excepción a la medición a valor razonable. Por tal razón, las mediciones a valor razonable requeridas o permitidas por la NIIF 3 no fueron excluidas del alcance de la NIIF 13.

\subsection{Definición de valor razonable}

\subsubsection{Descripción de la sección}

La definición de valor razonable en la NIIF 13, se expone como el precio que se recibiría al vender un activo o pagado para transferir un pasivo en una transacción ordenada entre participantes del mercado en la fecha de medición.

\subsubsection{Efectos del debido proceso}

Esta definición inicia en el borrador de discusión (IASB, 2006), en el que se define originalmente el valor razonable tal como se expresa en la versión definitiva. No obstante en el proyecto de norma del 2009 (IASB, 2009), se realizan algunas precisiones sobre los fundamentos de esta definición, ilustrando de manera más amplia, por ejemplo la noción de precio de intercambio contenido en la inicial definición de valor razonable, así como el supuesto de una operación hipotética en un mercado organizado.

En la NIIF 13, se mantiene la definición inicialmente propuesta y hace un desarrollo más amplio sobre las premisas del valor razonable, como por ejemplo precio de salida, mayor y mejor uso y transacciones. Establece un marco encaminado a estimar el precio en condiciones de un mercado ordenado, manteniendo la noción de intercambio, de esta forma el IASB transmite con mayor claridad que el valor razonable está basado en el mercado y no de acuerdo a una entidad específica.

Adicionalmente, presenta en las bases para conclusiones las diferencias entre las definiciones de valor razonable de los USGAAP (precio de salida) y las NIIF (valor de cambio). Algunas de las opiniones coinciden en que la propuesta de definir el valor razonable como un precio de salida actual, era apropiado debido a que la definición mantiene la idea de un intercambio entre partes independientes, conocedoras y dispuestas, incluidas en la anterior definición 
de valor razonable en las NIIF, incluyendo una visión más clara de una medición objetiva. Por otro lado, otras opiniones consideraron que un precio de entrada era más apropiado en algunas situaciones como por ejemplo en el reconocimiento inicial.

En definitiva, IASB concluyó que el precio de salida de un activo o un pasivo incorpora expectativas sobre los flujos de entrada y salidas futuras relacionadas con el activo o pasivo, desde la perspectiva de un participante del mercado, que tiene el activo o adeuda el pasivo a la fecha de medición.

Incluso si una entidad tiene la intención de generar flujos de efectivo de un activo mediante su uso en lugar de su venta, el precio de salida encarna las expectativas de flujos de efectivo derivados de la utilización de los activos, mediante la venta a un participante del mercado que ha de utilizarlo de la misma manera. Esto se debe a que un comprador en el mercado sólo pagaría por los beneficios que espera generar por el uso (o venta) de los activos. Así, el IASB llegó a la conclusión de que el precio de salida es una definición pertinente de valor razonable de los activos, independientemente de si una entidad tiene la intención de uso o de venta.

De manera similar, un pasivo da lugar a salidas de efectivo (u otros recursos económicos) cuando una entidad cumple con la obligación en el tiempo o cuando la transfiere a un tercero. Incluso si una entidad tiene la intención de cumplir con la obligación en el tiempo, el precio de salida encarna las expectativas de los flujos de efectivo relacionados debido a que un participante del mercado que asuma la obligación estaría obligado a cumplirla. Así, el IASB concluyo que el precio de salida es siempre una definición pertinente de valor razonable de los pasivos, independientemente de si una entidad tiene la intención de cumplir con la obligación o transferirla a un tercero.

\subsection{El activo o pasivo}

\subsubsection{Descripción de la sección}

La medición del valor razonable se realiza para un activo o pasivo en particular o para un grupo de activos (y/o pasivos). Para realizar la medición deben considerarse las características que un participante del mercado consideraría, tales como la ubicación del activo y restricciones existentes en la venta o uso del activo. También, para la medición debe considerarse la unidad de contabilización. La unidad de contabilización depende de la NIIF que permita o requiera la medición a valor razonable, salvo las excepciones que prevea la NIIF 13 (ver aplicación a activos financieros y pasivos financieros con posiciones compensadas en riesgos de mercado o riesgo de crédito de la contraparte).

\subsubsection{Efectos del debido proceso}

Debido a que la medición a valor razonable es una medición que considera las condiciones del mercado, el borrador de discusión propuso que la medición debe considerar las características los atributos específicos del activo o pasivo que un participante del mercado consideraría cuando establece el precio de ese activo o pasivo. Sin embargo, no se menciona particularmente las características del activo o pasivo.

El proyecto de norma, mantuvo la posición del borrador de discusión (IASB, 2006), argumentando que las características particulares de un activo o un pasivo, afectan el valor razonable si los participantes del mercado considerarían tales condiciones o restricciones. Adicionalmente incluyó algunos ejemplos sobre los atributos de un activo (condición del activo o posibles restricciones en su venta). También incluyó un apartado que considera la posibilidad de medir el valor razonable para grupos de activos, tales como un negocio o una unidad generadora de efectivo, debido a que otras NIIF requieren mediciones de valor razonable para grupos de activos (por ejemplo, la NIC 36 requiere la medición del valor razonable menos costos de venta para unidades generadoras de efectivo, con el fin de establecer su importe recuperable).

La NIIF 13 mantiene la visión acerca de las características particulares del activo o pasivo. Se argumenta que esta posición es consistente con las guías de medición existentes en las NIIF (Por ejemplo, la NIC 41 requiere la medición del valor razonable de un activo biológico o un producto agrícola en su condición y ubicación actual). Por tal razón, la NIIF concluyó que 
la nueva norma debía describir cómo medir el valor razonable, en vez de determinar qué se debía medir. Consecuentemente, incluye el concepto de unidad de contabilización, argumentando que las otras NIIF definen si la medición a valor razonable debe hacerse considerando un activo o pasivo individual o un grupo de activos o pasivos. (Por ejemplo, para la NIC 39 generalmente la unidad de contabilización es el instrumento financiero considerado individualmente).

\subsection{Transacción}

\subsubsection{Descripción de la sección}

La medición del valor razonable supone que el activo o pasivo se intercambia en una transacción ordenada entre participantes de mercado para vender el activo o transferir el pasivo en la fecha de la medición en condiciones de mercado presentes.

Adicionalmente, supone que la transacción de venta del activo o transferencia del pasivo tiene lugar en el mercado principal del activo o pasivo; o en ausencia de un mercado principal, en el mercado más ventajoso para el activo o pasivo.

\subsubsection{Efectos del debido proceso}

En el borrador de discusión (IASB 2006), no se desarrolla un acápite específico sobre este tema. No obstante a lo largo del documento se hace alusión a una transacción ordenada e hipotética en la fecha de la medición. En contraste, en el proyecto de norma del 2009 (IASB, 2009) se desarrolla una sección sobre las características de las transacciones. Se expone que la medición de valor razonable parte de una transacción ordenada, dado que se supone la exposición a un mercado en el que son habituales las transacciones de los activos o pasivos objetos de medición y por tanto no es una transacción forzada. Adicionalmente, se expone que el mercado en el que se desarrollan las transacciones es el más ventajoso al que tiene acceso la entidad.

Por otro lado, en ausencia de una transacción real para intercambiar el activo o transferir el pasivo en la fecha de medición, para esta medición se asumiría una transacción hipotética, para lo cual es necesario tener en cuenta las características del mercado y los participantes que realizarían la transacción.

Por último, la NIIF 13 mantiene la condición de una transacción ordenada. Adicionalmente, asume que las transacciones se llevan a cabo en el mercado principal del activo o pasivo y que en ausencia de éste mercado en el mercado más ventajoso para el activo o pasivo. En esta ocasión, se prioriza el principal mercado sobre el mercado más ventajoso. Ahora bien, para considerar el mercado principal la entidad deberá tener acceso al mismo. Se elimina la expresión de transacción hipotética, sin embargo, se supone una operación de cambio hipotético y ordenada.

En la NIIF 13 se argumenta que la noción de mercado más ventajoso es adecuada porque la mayoría de las entidades buscan maximizar el precio de venta de un activo o reducir el precio a pagar por transferir un pasivo. Sin embargo, existió la preocupación sobre la dificultad de identificar y seleccionar el mercado más ventajoso, más cuando un activo o un pasivo se intercambian en múltiples mercados en el mundo.

A pesar de que se pensó que en la mayoría de los casos el mercado principal y el mercado más ventajoso serían los mismos, se llegó a la conclusión que la atención debería centrarse en el mercado principal para el activo o para el pasivo, siendo éste el escenario en el que el activo o pasivo tiene mayor volumen de negociación o nivel de actividad. Debido a que el mercado principal es el mercado más líquido, es el que proporcionará los datos más representativos de una medición a valor razonable. Por tanto, la entidad no necesita realizar una búsqueda exhaustiva de los mercados a los que puede tener acceso, pues normalmente el mercado principal es aquel en el que la entidad desarrolla las transacciones. Así se respondió a las preocupaciones acerca de los costos en que se incurriría al buscar el mercado con mayor volumen.

\subsection{Participantes del mercado}

\subsubsection{Descripción de la sección}

Los supuestos que deben realizarse para la determinación del valor razonable deben desarrollarse 
considerando las hipótesis que los participantes del mercado realizarían para fijar el precio del activo o el pasivo, considerando que estos actúan en su mejor interés económico. Por tanto, no se deben asumir supuestos que no considerarían los participantes del mercado (supuestos específicos de la entidad).

Los participantes del mercado poseen todas las siguientes características de acuerdo con IASB (2011a):

“( a) Son independientes el uno del otro, es decir, no son partes relacionadas como se definen en la NIC 24, aunque el precio de una transacción entre partes relacionadas puede utilizarse como una variable para una medición del valor razonable si la entidad tiene evidencia de que la transacción se realizó en condiciones de mercado.

(b) Están debidamente informados, teniendo una comprensión razonable del activo o pasivo y queutilizan en la transacción toda la información disponible, incluyendo información que puede obtenerse a través de esfuerzos con la diligencia debida que son los usuales y habituales.

\section{(c) Son capaces de realizar una transacción para el activo o pasivo.}

(d) Tienen voluntad de realizar una transacción con el activo o pasivo, es decir están motivados pero no forzados u obligados de cualquier forma a hacerlo."

\subsubsection{Efectos del debido proceso}

El borrador de discusión (IASB, 2006) propuso que la estimación del valor razonable debe utilizar los supuestos que usarían los participantes del mercado cuando fijan el precio de un activo o un pasivo. La razón de esta conclusión es que el valor razonable es una medición basada en el mercado y no una medición específica de la entidad.

El SFAS 157 (FASB, 2011) definía los participantes del mercado como compradores y vendedores:
- Independientes.

- Debidamente informados acerca del activo o pasivo y de la transacción.

- Capaces de entrar en la transacción.

- Dispuestos (Pero no obligados) a comprar o vender el activo o pasivo.

La definición existente en las NIIF acerca de los participantes del mercado, los caracterizaba por estar interesados, estar debidamente informados y actuar en condiciones de independencia mutua.

El Consejo concluyó que las definiciones de participantes del mercado en las NIIF y en el SFAS 157, aunque diferentes en su redacción, eran consistentes entre sí. También consideró que la definición del SFAS 157 articulaba de una forma más clara el objetivo medición a valor razonable y que, por tal razón, se proponía como punto de partida la definición de participantes del mercado presente en éste.

El proyecto de norma mantuvo la posición del borrador de discusión, incluyendo un párrafo en donde se especificaban las características que los participantes del mercado considerarían al fijar el precio de un activo o pasivo y que, por tanto, deben tenerse considerarse en la medición. Al respecto, se argumentó que la entidad no tendría que identificar participantes específicos del mercado. Por el contrario, debía centrarse en identificar características que distinguirían el activo o pasivo para los participantes del mercado, considerando factores específicos para:

- El activo o pasivo.

- El mercado más ventajoso para el activo o pasivo.

- Los participantes del mercado con los cuales la entidad entraría en una transacción en el mercado.

La NIIF 13, finalmente ratifica la posición del Proyecto de norma. A continuación se comentan algunas de las respuestas analizadas con ocasión de los comentarios recibidos al proyecto de norma.

Con respecto a la independencia el Consejo convino aclarar que una transacción entre partes relacionadas puede ser usada como un dato de entrada para 
la medición a valor razonable, si la entidad tiene evidencia de que la transacción se realizó en términos de mercado.

Frente a las condiciones de conocimiento del activo o el pasivo, algunos argumentaron que deberían considerarse las asimetrías de información. En otras palabras, argumentaban que un participante del mercado generalmente tendría menos información sobre el activo o el pasivo que la que tendría la entidad que reporta. El Consejo concluyó que un participante del mercado dispuesto a entrar en una transacción, desarrollaría los esfuerzos necesarios para obtener el conocimiento necesario respecto del activo o pasivo. Adicionalmente, un participante del mercado incluiría el riesgo asociado en la determinación del valor razonable.

\subsection{El precio}

\subsubsection{Descripción de la sección}

La estimación del valor razonable se enfoca en el precio que se recibiría por la venta de un activo o se pagaría por la transferencia de un pasivo en una transacción ordenada en el mercado principal (o más ventajoso) en la fecha de la medición en condiciones de mercado presentes, es decir, un precio de salida. Independientemente de si ese precio es observable directamente o estimado utilizando otra técnica de valoración.

\subsubsection{Efectos del debido proceso}

El enfoque propuesto se encuentra presente desde el borrador de discusión en el que se establece que el objetivo de la medición a valor razonable es determinar el precio que sería recibido para vender el activo o pagado para transferir el pasivo a la fecha de valoración (precio de salida).

En el proyecto de norma (IASB, 2009) se reafirma este criterio, además que define que el precio puede ser observado directamente del mercado, y en ausencia de éste, podrá estimarse a través de una técnica de valoración, en la que se consideren las características de los participantes del mercado en el que se podría llevar a cabo la transacción.
Adicionalmente, se amplía la orientación al establecer que los costos de transacción no se incluyen en las mediciones del valor razonable dado que no son una característica del activo o del pasivo, sino son específicos de la transacción, sin embargo se tienen en cuenta para determinar el mercado más ventajoso. Estos costos no incluyen los gastos de transporte, si la ubicación es una característica del activo, estos deben incidir en el precio.

Por último, en la versión definitiva se mantiene la definición del valor razonable como el precio de salida, por la venta de un activo o por transferir un pasivo, independientemente de si el precio es directamente observable o se estima a través de una técnica de valoración. Los costos de transacción no se tienen en cuenta en el precio, por tanto no deben reducir ni incrementar el activo o el pasivo. Esta decisión es consistente con los requisitos para determinar el valor razonable en otras NIIF, por ejemplo la NIC 40 sobre agricultura. Se mantiene que los costos de transporte se derivan de un evento que si modifica las características del activo por tanto no tendrán el tratamiento de los costos de transacción.

\subsection{Aplicación a activos no financieros}

\subsubsection{Descripción de la sección}

Cuando se determine el valor razonable de un activo no financiero, se considerará el precio que un participante del mercado fijaría teniendo en cuenta que el activo se utiliza en su máximo y mejor uso. Un participante del mercado lograría el "máximo y mejor uso" mediante la utilización del activo o mediante la venta a otro participante del mercado que maximice los beneficios en la utilización del activo. El máximo y mejor uso tendrá en cuenta la utilización del activo que sea físicamente posible, legalmente permisible y financieramente factible. Por ser una medida del mercado, el valor razonable se determina a partir de la perspectiva de los participantes del mercado, aunque la entidad pretenda un uso distinto. Sin embargo, se presume que el uso actual es su máximo y mejor uso, a menos que existan circunstancias evidentes que sugieran lo contrario. 
Se consideran las siguientes dos premisas de valuación, que deben ser consistentes con el máximo y mejor uso: (i) el máximo y mejor uso supone la venta a un participante del mercado que utilizará el activo junto con otros activos, y (ii) el máximo y mejor uso supone la venta a un participante del mercado que utilizará el activo de forma aislada, obteniendo la mayor cantidad de beneficios económicos posibles.

\subsubsection{Efectos del debido proceso}

El borrador de discusión (IASB, 2006) apoyaba el principio del SFAS 157 (FASB, 2011) que contenía la premisa del máximo y mejor uso. Comparó este concepto con el valor en uso incorporado en la NIC 36 y afirmó que este último era una medida específica de la entidad, mientras que la medida de valor razonable pretende considerar la perspectiva de un participante del mercado. Esta medición sobre el máximo y mejor uso, incorpora dos premisas de valoración:

- Premisa de uso: en donde el precio del activo sería el que se obtendría por la venta a un participante del mercado suponiendo que el máximo y mejor uso es la utilización del activo junto con otros activos y pasivos.

- Premisa de intercambio: en donde el precio del activo sería el que se obtendría por la venta a un participante del mercado suponiendo que el máximo y mejor uso es la utilización del activo de forma aislada.

El proyecto de norma mantuvo la posición del borrador de discusión, incluyendo las consideraciones sobre la posibilidad física, permisibilidad legal y factibilidad financiera. Como respuesta a los usuarios de los estados financieros también se propuso que cuando un grupo de activos no financieros tenga un uso distinto a su máximo y mejor uso la entidad debía revelar por separado el valor razonable de los activos asumiendo su uso actual y un valor incremental que resulta de la diferencia entre el uso actual de los activos y su máximo y mejor uso.

Quienes respondieron al borrador de discusión cuestionaron la posibilidad real que tendría una entidad para determinar si los participantes del mercado utilizarían un activo de forma diferente a la mane- ra como lo utiliza la entidad. Por tal razón, el documento clarificó que las entidades no deben realizar búsquedas exhaustivas sobre el máximo y mejor uso si no existe evidencia de que el uso actual no es su máximo y mejor uso.

Finalmente, la NIIF 13 mantiene el principio del máximo y mejor uso presente en el proyecto de norma, así como sus principales requerimientos. Quienes respondieron al proyecto de norma consideraron que era complejo y difícil de aplicar el requerimiento de la determinación del valor incremental, cuando el uso actual de un grupo de activos es diferente de su máximo y mejor uso. Por esta razón la NIIF 13 elimina esta propuesta y solamente requiere que la entidad revele este hecho junto con la razón por la cual la entidad no utiliza el activo en su máximo y mejor uso.

Debido a que el proyecto de norma contenía las dos premisas de valuación denominadas "de uso" y "de intercambio", muchos de los que respondieron afirmaron que el nombre de las premisas no reflejaba de manera adecuada el objetivo de la medición, porque en los dos casos se presume que el activo es intercambiado en una transacción hipotética. También la premisa denominada como "en uso" podría llevar a confusión, en la medida en que la NIC 36 define el término "valor en uso", aunque, como se anotó anteriormente, tienen significados diferentes. Por estas razones las premisas de valuación "uso e intercambio", en la NIIF 13 son renombradas de una forma que se entienda el objetivo de la premisa: (i) El uso del activo junto con otros activos, o (ii) el uso del activo de forma individual.

\subsection{Aplicación a pasivos e instrumentos de patrimonio propios de una entidad}

\subsubsection{Descripción de la sección}

La NIIF 13 supone que un pasivo financiero o no financiero o un instrumento de patrimonio propio de una entidad (por ejemplo participaciones en el patrimonio emitidas como contraprestación en una combinación de negocios) se transfiere a un participante de mercado en la fecha de la medición. La transferencia de un pasivo o un instrumento de patrimonio propio de una entidad supone que: i) Un 
pasivo permanecería en circulación y se requeriría al participante de mercado receptor de la transferencia satisfacer la obligación. El pasivo no se liquidaría con la contraparte o extinguiría de otra forma en la fecha de la medición. ii) Un instrumento de patrimonio propio de una entidad permanecería en circulación y el participante de mercado receptor de la transferencia cargaría con los derechos y responsabilidades asociados con el instrumento. El instrumento no se cancelaría, extinguiría de otra forma en la fecha de la medición.

\subsubsection{Efectos del debido proceso}

El borrador de discusión (IASB, 2006) establece que la medición de valor razonable de un pasivo es el valor por el cual sería transferido a un participante en la fecha de medición, adicionalmente que el riesgo de incumplimiento del pasivo es el mismo antes y después de su transferencia. El riesgo de incumplimiento se refiere al riesgo de que la obligación no se cumpla y por tanto, afecta el valor por el cual se transfiere. En este borrador no se hace alusión a lo relacionado con instrumentos de patrimonio propios de la entidad.

Posteriormente, en el proyecto de norma, se amplían los criterios de las mediciones de valor razonable del pasivo e incorpora lo relacionado con instrumentos de patrimonio. Se establece que en el caso de los pasivos, en muchos casos es posible que no exista un mercado observable para la transferencia de esos pasivos, por lo que la entidad determinará el valor razonable con la misma metodología que la contraparte del pasivo utilizaría para medir su correspondiente activo. Por tanto, si hay un mercado activo para las transacciones entre partes que tienen títulos de deuda como un activo, el precio observado es también el valor razonable del pasivo para el emisor. Sin embargo, se debe ajustar el precio observado para el activo, de acuerdo a las condiciones del pasivo que se está midiendo.

En el proyecto se amplía la aplicación del riesgo de incumplimiento en la medición de los pasivos, al medir el valor razonable de un pasivo, la entidad considerara su riesgo de crédito (solvencia) y cualquier otro riesgo que pueda influir en la probabilidad de que la obligación no sea cumplida.
Respecto de las restricciones de transferencia que pueda tener un pasivo, el proyecto propone que éste no es un factor que afecte el valor razonable del mismo, dado que el cumplimiento de la obligación es exigible indistintamente de este factor a la entidad.

Con respecto a los instrumentos de patrimonio, el proyecto establece que el objetivo de la medición del valor razonable es el mismo, sin embargo el emisor de instrumento de esta clase puede salir de ese instrumento sólo si éste deja de existir o si la entidad recompra el instrumento. Por esta razón el valor razonable se determinará desde la perspectiva de un participante del mercado que mantiene el instrumento como activo. En la versión definitiva se desarrolla con mayor detalle los criterios a tenerse en cuenta en las mediciones de valor razonable tanto del pasivo como de los instrumentos de patrimonio.

Con respecto al pasivo se llegó a la conclusión de que el concepto de transferencia es necesario para la medición de valor razonable, ya que éste incorpora las expectativas de los participantes acerca de la liquidez, la incertidumbre y otros factores asociados con la obligación, independientemente de que el emisor del pasivo resuelva o no transferirlo.

Se mantiene el criterio de que al no existir un mercado específico del pasivo, éste podrá medirse a partir del valor razonable de estos mismos instrumentos pero desde la perspectiva del inversionista.

Aun cuando se mantiene la posición del proyecto respecto de la consideración del riesgo de incumplimiento en la estimación del valor razonable de los pasivos, en el estándar se amplía los criterios al incluir, por ejemplo, que esto dependerá de si es una obligación financiera o no financiera, y si existen condiciones de mejora crediticia relacionadas con el pasivo, en el caso de ser garantizados.

La junta concluye que existen dos diferencias fundamentales entre la medición del valor razonable de un activo y un pasivo. En primer lugar, las restricciones de transferencia del pasivo se relacionan con el cumplimiento de la obligación, mientras que las restricciones de la transferencia de un activo se relacionan con la comercialización del mismo. 


\subsection{Aplicación a activos financieros y pasivo financieros con posiciones compensadas en riesgos de mercado o riesgo de crédito de la contraparte}

\subsubsection{Descripción de la sección}

Si una entidad gestiona un grupo de activos financieros y pasivos financieros sobre la base de su exposición neta a los riesgos de mercado o al riesgo de crédito, es posible aplicar una excepción a la unidad de contabilización (ver sección 3.3 sobre el activo o pasivo) para la medición del valor razonable. Esta excepción permite que la medición no se haga considerando la unidad de contabilización (generalmente considerando cada instrumento por separado), sino determinando el valor razonable del grupo de activos y pasivos. Es decir, se permite que una entidad mida el valor razonable de un grupo de activos financieros y pasivos financieros sobre la base del precio que recibiría por vender una posición neta larga (activo) o por transferir una posición neta corta (obligación).

\subsubsection{Efectos del debido proceso}

El borrador de discusión, basado en el SFAS 157 (FASB, 2011), no contenía ninguna excepción a la unidad de contabilización. Sin embargo, se animaba a los participantes del proceso a presentar sus opiniones sobre si los planteamientos propuestos en el SFAS 157, junto con la unidad de contabilización presente en la NIC 39, resultaría en que las entidades determinarían el valor razonable utilizando valuaciones de portafolios de instrumentos considerados en conjunto, o una medición de los instrumentos individualmente considerados.

El proyecto de norma mantuvo el principio del borrador de discusión que no contenía ninguna excepción a la unidad de contabilización. El Consejo argumentó que los actuales requisitos de la guía de aplicación de la NIC 39 (Guía de Aplicación - GA $71 / 72$ ), requieren que la medición de valor razonable se haga al nivel de cada instrumento individualmente considerado.

Algunos de los que comentaron el borrador de discusión, respondieron que el valor razonable debía considerar un "factor de bloque" (blockage factor). En su opinión, en estos casos una entidad recibiría un menor valor por la venta del grupo de activos, que aquel que recibiría si vendiera cada instrumento por separado. El Consejo argumentó que como se notó anteriormente, la unidad de contabilización es el instrumento individual. Adicionalmente, el objetivo de medición del valor razonable presume que los participantes del mercado actúan en su mejor interés económico. Es decir, que un participante del mercado vendería el activo por el precio más ventajoso que podría recibir por el instrumento. Así, si una entidad en particular decide vender el conjunto de activos, recibiendo un valor inferior al que recibiría vendiendo los instrumentos por separado, es una circunstancia específica de la entidad que no debe incorporarse en la determinación del valor razonable.

En los fundamentos para las conclusiones de la NIIF 13, el Consejo reconoce que el proyecto de norma proponía utilizar la premisa de "intercambio" para todos los activos financieros. Esto, porque concluyó que una entidad no obtiene valores incrementales de poseer un activo financiero dentro de un portafolio. Esta propuesta fue una de las más debatidas por los que respondieron al proyecto de norma. Quienes respondieron afirmaban que este requerimiento llevaba a que el valor razonable no reflejaba el hecho de que los activos financieros se manejaran sobre la base de la exposición neta al riesgo de mercado y al riesgo de crédito. A su vez, esto llevaría a desvincular la medición de tales instrumentos para propósitos del reporte financiero, de la medición elaborada para propósitos de la administración interna del riesgo en la entidad.

Debido a esto, la NIIF 13 incluye la excepción descrita para activos financieros y pasivos financieros con posiciones compensadas para el riesgo de mercado o riesgo de crédito de una contraparte en particular. Como resultado, se mantiene la vinculación de la valoración de los instrumentos financieros para propósitos de los reportes financieros con la valoración para efectos de las prácticas de administración de riesgos interna de las entidades. Cuando un participante del mercado posee un grupo de instrumentos financieros y unas preferencias de riesgo deter- 
minadas, es mucho más probable que fije el precio de los instrumentos de forma compensada. Por esta razón, una medición en términos netos sería consistente con la definición de valor razonable.

\subsection{Valor razonable en el reconocimiento inicial}

\subsubsection{Descripción de la sección}

Para el caso de las mediciones de valor razonable en el reconocimiento inicial la NIIF 13 define que si otra NIIF requiere o permite que una entidad mida un activo o un pasivo inicialmente a valor razonable y el precio de la transacción difiere del valor razonable, la entidad reconocerá la ganancia o pérdida resultante en el resultado del periodo a menos que la NIIF especifique otra cosa.

\subsubsection{Efectos del debido proceso}

Inicialmente el borrador de discusión establece que cuando se adquiere un activo o un pasivo se asume en un intercambio de transacciones, el precio representa el precio pagado para adquirir el activo o recibido para asumir la obligación (precio de entrada). En contraste, el valor razonable del activo o del pasivo representa el precio que sería recibido por vender un activo o pagado para transferir el pasivo (precio de salida). Conceptualmente, los precios de entrada y de salida son diferentes, pues las entidades no necesariamente venden activos a los precios adquiridos, del mismo modo, las entidades no necesariamente transfieren los pasivos por los valores recibidos cuando fueron asumidos.

En muchos casos el precio de la transacción en la que se adquiere el activo o el pasivo, coincide con el precio de salida, por tanto éste representa el valor razonable en el reconocimiento inicial.

Para identificar esta situación, el borrador expone que la entidad deberá tener en cuenta factores específicos de la transacción y del activo o del pasivo. Por ejemplo: transacción entre las partes relacionadas, condiciones de la transacción, los costos de transacción, el mercado en el ocurre la transacción.
Por su parte el proyecto de norma mantiene los lineamientos del borrador y ejemplifica el caso de una combinación de negocios y activos biológicos. Incorpora el criterio contable en el caso de que una NIIF requiera o permita a una entidad medir un activo o pasivo inicialmente al valor razonable y el precio de la transacción difiere de éste, la entidad reconoce la diferencia en los resultados a menos que las NIIF lo requiera de otra manera.

En la definición de la NIIF 13, IASB a partir de las sugerencias recibidas al proyecto concluye que la inactividad de un mercado no es un indicador de que el precio de la transacción no pueda representar el valor razonable del activo o del pasivo, sino que es un indicador de que la entidad debe seguir determinando si éste precio es una representación del valor razonable.

Adicionalmente, llega a la conclusión de que el valor razonable debe medirse independientemente de que se genere una ganancia o una pérdida en el reconocimiento inicial de un activo o un pasivo. Sin embargo, existieron algunas opiniones sobre que el precio de la transacción es la mejor prueba de valor razonable en el reconocimiento inicial.

En consecuencia, se mantiene la posición de que si la correspondiente NIIF del activo o del pasivo no específica lo contrario, las diferencias entre el precio de la transacción y el valor razonable se debe reconocer en las ganancias o pérdidas. Para lo cual, por ejemplo, se modificó la NIC 39 y NIIF 9 para aclarar que el valor razonable de los instrumentos en el reconocimiento inicial debe ser medido de acuerdo con la NIIF 13

\subsection{Técnicas de valuación}

\subsubsection{Descripción de la sección}

La entidad debe usar técnicas de valoración que sean apropiadas a la medición, maximizando el uso de variables observables en el mercado y minimizando el uso de variables no observables en el mercado. Existen tres técnicas de valoración ampliamente utilizadas: 
- Enfoque del mercado: Utiliza información relevante generada por transacciones por el mercado. Dentro de estas técnicas se encuentran la utilización de múltiplos o las matrices de fijación de precios.

- Enfoque del ingreso: Consiste en el descuento de flujos futuros para la determinación del valor razonable. Dentro de estos se resaltan las técnicas de valor presente, técnicas de fijación de precios de opciones o el método del exceso de ganancias futuras.

- Enfoque del costo: Refleja el valor que sería necesario para sustituir el activo en sus condiciones presentes en el momento de la medición. Actualmente es conocida como una técnica para determinar el valor actual o de reposición.

Se requiere que cuando el valor razonable en la medición inicial sea el precio de la transacción, la técnica de valoración se ajuste para que el valor inicial se iguale al resultado de la técnica de valoración de manera que esta última recoja las variables de mercado presentes en el precio de la transacción.

Las técnicas de valoración se aplicarán de manera consistente durante los períodos. Sin embargo, un cambio en las circunstancias, podrá hacer necesario un cambio o un ajuste en la técnica de valoración. Dicho cambio, se contabilizará como un cambio en una estimación contable, de acuerdo con la NIC 8. Sin embargo, las revelaciones requeridas por la NIC 8 no son necesarias.

\subsubsection{Efectos del debido proceso}

El borrador de discusión (IASB, 2006) no propuso como un tema específico de consulta las técnicas de valuación, pero en el SFAS 157 (FASB, 2011) que era la base de la propuesta estaban incorporadas las técnicas de valoración referidas como enfoques de mercado, ingreso y costo.

El proyecto de norma, incorpora los tres enfoques de las técnicas de medición dentro del cuerpo de la propuesta, manteniendo consistencia con el SFAS 157. También, se aclara que el documento no propone una jerarquía de las técnicas de valuación porque éstas deben utilizarse considerando las circunstancias particulares de la medición. En otras palabras, en ciertas situaciones una técnica de valuación puede resultar más apropiada que otras.

Algunos de los que respondieron al borrador de discusión, cuestionaron si el enfoque del costo era consistente con la medición a valor razonable. Ellos argumentaban que el enfoque del costo era una medida de entrada y no necesariamente una medida de salida. El Consejo argumenta su decisión basado en el principio económico de la sustitución, que establece que un participante del mercado no pagará más que el valor por el cual él podría remplazar la capacidad de servicio del activo en cuestión. Basado en estos argumentos el Consejo mantuvo el enfoque del costo, como un medio relevante de medir el valor razonable, particularmente para activos no financieros valorados bajo la premisa del uso del activo junto con otros activos.

El proyecto de norma también propone que cualquiera que fuera la técnica de medición elegida, esta debería incorporar un ajuste por riesgo, si los participantes del mercado también lo hicieran cuando determinan el precio del activo o pasivo. Por último, el proyecto de norma propuso que las técnicas de medición se usaran de manera consistente, no obstante, éstas pueden cambiarse cuando una nueva técnica o una nueva forma de aplicación lleven a una medición de valor razonable que sea más representativa. En tales casos, el cambio de la técnica de medición se contabilizará como un cambio en una estimación contable de acuerdo con la NIC 8 y se deberá revelar el hecho del cambio, las razones y sus efectos sobre la medición.

La NIIF 13 mantuvo los tres enfoques de las técnicas de valoración (mercado, ingreso y costo). Estas son mencionadas en el cuerpo del estándar y se detallan en la guía de aplicación.

Respondiendo a la solicitud de varios de los que participaron en el proceso de discusión, la NIIF 13 incluye una descripción de los ajustes de la valoración que deberían hacerse bajo ciertas circunstancias tales como el riesgo de incumplimiento o la medición de la incertidumbre causada por una disminución del nivel de negociación del mercado: 
- Ajustes a las técnicas de valoración, para tener en cuenta una característica del activo o pasivo que la técnica de valoración no incorpora.

- La elección del punto dentro del diferencial de precios comprador - vendedor, que represente de mejor forma el valor razonable, dependiendo de las circunstancias.

- Ajustes para incorporar el riesgo de incumplimiento.

- Ajustes para incorporar el riesgo generado por la incertidumbre en la medición.

La propuesta del proyecto de norma, de requerir revelaciones similares a las de la NIC 8 (naturaleza, razón y efecto del cambio) cuando se cambia una técnica de medición (estimación contable) no fue apoyada por quienes respondieron porque consideraron que era en muchos casos complejo determinar si el cambio en el valor razonable es atribuible al cambio en la técnica de valoración o al cambio de otras variables. Por tanto, cuando ocurre un cambio en la técnica de valoración, la NIIF 13 sólo requiere la revelación del cambio y la razón del mismo.

\subsection{Datos usados en las técnicas de valoración}

\subsubsection{Descripción de la sección}

La NIIF 13 establece que las técnicas de valoración utilizadas para medir el valor razonable maximizarán el uso de variables observables relevantes y minimizará el uso de variables no observables.

\subsubsection{Efectos del debido proceso}

Inicialmente, en el borrador de discusión los datos se refieren en general a los supuestos del mercado, de los participantes, uso, precios del activo o del pasivo, incluyendo supuestos sobre los riesgos asumidos, por ejemplo en las valoraciones técnicas. Los datos de entrada pueden ser observables o no observables.

Los datos observables son las entradas que reflejan el mercado, los supuestos de los participantes, el uso, los precios del activo o pasivo, desarrollados sobre la base de datos del mercado, obtenidos de fuentes independientes de la entidad que reporta, y los datos no observables son los datos que refleja la propia en- tidad que reporta, los supuestos sobre los participantes del mercado. Las técnicas de valuación usadas para medir el valor razonable deben maximizar el uso de datos observables y minimizar el uso de datos no observables.

proyecto de norma (IASB, 2009) mantenía los criterios del documento borrador y ampliaba lo relacionado con la maximización de los datos observables, al establecer que la entidad puede determinar datos observables que pueden requerir de ajustes en tal caso la medición del valor razonable se clasificaría en un nivel inferior.

Por último en la NIIF 13, se decide que un insumo necesario en el uso de una técnica de valoración es el ajuste de acuerdo al nivel de riesgo del activo o del pasivo, dado que éste ajuste lo hacen los participantes del mercado. Se mantiene que la entidad debe maximizar el uso de datos observables y reducir al mínimo el uso de datos no observables.

Dado que algunas de las observaciones hechas al proyecto muestran su preocupación por el uso de datos observables en escenarios de crisis como la del 2007, el estándar se centra en datos observables relevantes. Sin embargo, la entidad requerirá hacer ajustes importantes a éstos dadas las características del activo o del pasivo, y las circunstancias del mercado en la fecha de medición.

La aplicación de las primas y descuentos en una medición del valor razonable se relaciona con las características del activo o pasivo que se miden a valor razonable y su unidad de cuenta. Se especifica que cuando un nivel 1 de entrada no está disponible, la medición de valor razonable debe incluir las primas o descuentos, a partir de las consideraciones de los participantes del mercado.

Se hace referencia a datos basados en precios de oferta y demanda (Bid-Ask spread), la entidad tendrá que hacer una evaluación de la información de ofertademanda de un activo o un pasivo para determinar el spread más representativo del valor razonable en determinadas circunstancias. La junta concluye que este método es relevante para los instrumentos financieros y en mercados en que un intermediario (por 
ejemplo, un corredor) es necesario para transacciones entre un comprador y un vendedor (es decir, cuando el comprador y el vendedor necesita un intermediario para encontrarse uno al otro). Cuando se mide el valor razonable de un activo o un pasivo no financiero, la noción de un spread no es relevante ya que los compradores y vendedores en el mercado principal (o el más ventajoso) se han encontrado y se supone que han negociado el precio de la transacción (valor razonable) y no requieren de intermediación.

\subsection{Jerarquías del valor razonable}

\subsubsection{Descripción de la sección}

Las mediciones hechas a valor razonable deben clasificarse en tres niveles jerárquicos, de manera que se mejore la coherencia y comparabilidad de tales mediciones:

- Nivel 1: Las mediciones clasificadas en el nivel 1 son aquellas que utilizan precios cotizados sin ajustar, para activos o pasivos idénticos en mercados activos a los que la entidad puede acceder en la fecha de medición. En este nivel no se utilizan ajustes ni técnicas de valoración cuando se determina el valor razonable.

- Nivel 2: Las mediciones clasificadas en el nivel 2 utilizan variables observables en el mercado pero que no son precios cotizados sin ajustar. Estas variables de mercado pueden incluir precios de mercado para activos o pasivos similares, precios de mercado para activos o pasivos idénticos pero en mercados no activos, tasas de mercado de referencia o curvas de rendimiento observables en el mercado.

- Nivel 3: Las mediciones de nivel 3 utilizan variables no observables en el mercado y por tanto reflejarán las mejores estimaciones de la entidad acerca del precio hipotético que se lograría en una transacción ordenada entre participantes del mercado en la fecha de medición.

Debido a que en una medición de valor razonable pueden existir variables que pertenezcan a diferentes niveles, la NIIF 13 requiere que la medición se clasifique en su totalidad en el mismo nivel de la jerarquía de valor razonable que la variable de nivel más bajo que sea de importancia relativa para la medición. Así, cuando se utiliza una técnica de medición en donde las variables más importantes del modelo son variables observables del mercado, la medición se clasificará en el nivel 2. Si por el contrario, la medición se ve afectada principalmente por variables no observables en el mercado, entonces la medición se clasificará en el nivel 3.

\subsubsection{Efectos del debido proceso}

Debido a que no existía una jerarquía única en las NIIF sobre las mediciones de valor razonable, el borrador de discusión propuso los tres niveles existentes en el SFAS 157 (FASB, 2011). Igualmente, incorporó la prescripción del SFAS 157 en relación con la clasificación de la medición a valor razonable en el mismo nivel que se clasifique la variable representativa de nivel más bajo.

En 2009, el proyecto de norma publicado, mantuvo los niveles propuestos por el borrador de discusión. En este se argumentó que el nivel 1 (precios cotizados en mercados activos, sin ajustar) generalmente representa la mejor evidencia del valor razonable y en caso de existir tales precios, deben ser utilizados para su determinación. También propuso una definición de mercado activo que era consistente con las definiciones existentes en las NIIF:

"Un mercado en el que las transacciones para el activo o el pasivo, toman lugar con suficiente frecuencia y volumen como para proveer información sobre los precios de manera continua" (IASB, 2009).

Adicionalmente, se propuso la posibilidad de que las entidades utilicen modelos alternativos de fijación precios, si mantenían una gran cantidad de activos y pasivos cuyos precios de mercado existían pero no eran fácilmente accesibles. Tal requerimiento es una excepción a la prescripción de que deberían utilizarse siempre precios cotizados, si son observables, Sin embargo, el Consejo consideró apropiado permitirlo por razones de costo beneficio.

Sobre las mediciones a nivel 2, el Consejo concluyó que era apropiado incluirlo porque estas mediciones 
son menos subjetivas que aquellas mediciones clasificadas en el nivel 3.

En las mediciones clasificadas en el nivel 3, algunos de quienes respondieron expresaron que podría ser errado describir tales medidas que utilizan principalmente datos no observables, como mediciones de valor razonable. Para ellos, tales formas de medición generalmente incluirían factores específicos de la entidad que un participante del mercado, podría no incluir cuando establece el precio de un activo o un pasivo. El Consejo concluyó que, sin importar las variables utilizadas para su determinación, la medición a valor razonable persigue el mismo objetivo. De la misma forma, el límite entre las mediciones de nivel 2 y nivel 3 es inevitablemente subjetivo. Por tanto, además de complejo, sería inadecuado requerir que las mediciones de nivel 3, basadas en tales criterios subjetivos no fueran denominadas como mediciones de valor razonable.

El proyecto de norma también incluyó en la guía de aplicación, ejemplos de las variables de nivel 2 y 3 y criterios para la medición del valor razonable cuando el nivel de actividad de un activo o pasivo ha disminuido significativamente.

La NIIF 13 mantiene los principios y el contenido del proyecto de norma. Con respecto a la medición del valor razonable cuando el nivel de actividad de un activo o pasivo ha disminuido significativamente. El Consejo decidió hacer explícito que las orientaciones contenidas en la norma son aplicables cuando el nivel de actividad ha disminuido significativamente y no para activos o pasivos para los cuales generalmente no hay datos de mercado.

Adicionalmente, el Consejo concluyó que al aplicar la NIIF 13, una entidad debe asegurarse que el precio de la transacción provenga de una transacción ordenada y no centrarse exclusivamente en el nivel de actividad del mercado, porque aún en mercados con poca actividad, la transacción puede ser ordenada y ser representativa del valor razonable. Si una entidad no tiene información para determinar si la transacción es ordenada, deberá realizar análisis adicionales para determinar el valor razonable.

\subsection{Revelaciones}

\subsubsection{Descripción de la sección}

Dentro de los criterios generales de revelaciones de la NIIF 13, se establece que una entidad revelará información que ayude a los usuarios de sus estados financieros a evaluar los dos elementos siguientes: i) Para activos y pasivos que se miden a valor razonable sobre una base recurrente o no recurrente en el estado de situación financiera después del reconocimiento inicial, las técnicas de valoración y las variables utilizadas para desarrollar esas mediciones; $y$, ii) Para mediciones del valor razonable recurrentes utilizando variables no observables significativas (nivel 3), el efecto de las mediciones sobre el resultado del periodo $\mathrm{u}$ otro resultado integral para el periodo.

\subsubsection{Efectos del debido proceso}

Inicialmente en el borrador de discusión (IASB, 2006) se establece que para los activos y pasivos que se midan a valor razonable, recurrentemente, en los periodos posteriores al reconocimiento inicial, se revelará información que permita a los usuarios de la información financiera evaluar los insumos utilizados para el desarrollo de tales mediciones. En caso de mediciones recurrentes del nivel 3 , se deberá informar sobre los efectos en las ganancias o en los activos netos del periodo.

Para cada categoría de activo o pasivo medido a valor razonable se revelará: i) la determinación del valor razonable en la fecha de presentación; ii) la jerarquía del valor razonable; iii) para el caso del nivel 3 la conciliación de los saldos iniciales y finales; iv) las ganancias o pérdidas totales para el periodo, el lugar donde son reportadas; $\mathrm{y} v$ ) en los periodos anuales solamente, la técnica de valoración utilizada y las razones si hubo un cambio en la técnica de valoración durante el periodo.

Posteriormente, en el proyecto de norma del 2009 se mantuvo la intensión de las revelaciones respecto de los usuarios de la información y demás requerimiento del borrador. Se adiciona como revelación, las transferencias significativas entre el Nivel 1 y Nivel 2 y las razones para esas transferencias. 
Por último en la NIIF 13, se amplían considerablemente los criterios de revelación. Se hace una distinción entre las mediciones de valor razonable recurrente y no recurrente, información que no contemplaba el proyecto de norma.

Requiere de información cuantitativa sobre la determinación del valor razonable clasificado en el Nivel 3 , exige una conciliación entre el saldo inicial y el saldo final de las partidas para establecer las perdidas realizadas y no realizadas, análisis de sensibilidad de la medición dado el uso de datos no observables, el procedimiento usado para la determinación del valor razonable.

\section{Conclusiones}

Luego del análisis de las secciones que componen la NIIF 13 y el desarrollo evolutivo en estos aspectos durante la construcción de la norma, a partir de lo expuesto en el borrador de discusión del 2006, el proyecto de norma del 2009 y lo planteado finalmente en la NIIF 13, se evidencian tres escenarios que marcan el debido proceso seguido por IASB en la definición de esta norma, tal como se expone en la Ilustración 1.

Ilustración 1. Evolución del debido proceso de la NIIF $13^{3}$
El análisis realizado permitió identificar que algunas premisas son planteadas en la propuesta inicial de IASB. En algunos casos, algunas de éstas fueron mencionadas de manera muy general y en otros tuvieron mayor desarrollo. De igual forma, otras premisas definidas en la NIIF 13, son resultado del debido proceso, dado que no estaban incorporadas en los planteamientos iniciales del borrador de discusión.

Lo anterior permitió identificar tres escenarios de construcción de la NIIF 13. El primero corresponde a las premisas que fueron inicialmente planteadas, argumentadas a lo largo del proceso y que finalmente se mantuvieron en la NIIF 13. En el segundo escenario se identifican las premisas que de igual manera fueron planteadas desde el inicio del proceso y como resultado de los comentarios recibidos a los textos expuestos para discusión, se consideró pertinente la reconsideración de los criterios inicialmente expuestos. En un último escenario se identifican las premisas que no fueron incluidas en la propuesta inicial, sino que son construcciones generadas por los comentarios y deliberaciones del proceso. La tabla 2 presenta una clasificación de las secciones de la NIIF 13, de acuerdo con el proceso de evolución identificado.

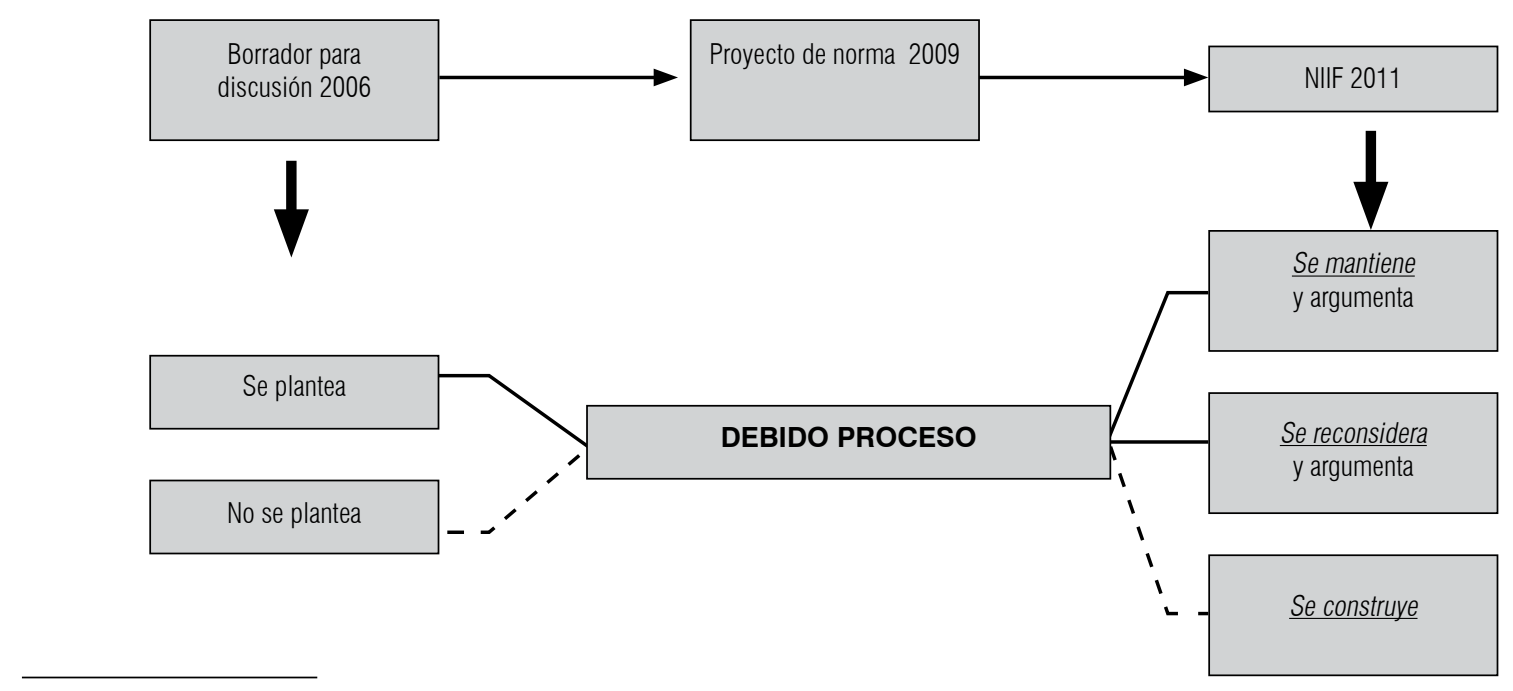

3 Fuente: Elaboración propia. 
Tabla 2. Clasificación del efecto del debido proceso en la NIIF $13^{4}$

\begin{tabular}{|l|c|c|c|}
\hline \multicolumn{1}{|c|}{ Sección } & Se mantiene & Se reconsidera & Se construye \\
\hline 1. Alcance & & $\checkmark$ & \\
\hline 2. Definición & $\checkmark$ & & \\
\hline 3. Activo y pasivo & $\checkmark$ & & \\
\hline 4. Transacción & $\checkmark$ & & \\
\hline 5. Participantes & $\checkmark$ & & \\
\hline 6. El precio & $\checkmark$ & & \\
\hline 7. Aplicación a activos no financieros & & & \\
\hline $\begin{array}{l}\text { 8. Aplicación a pasivos e instrumentos de patrimonio } \\
\text { propios de la entidad }\end{array}$ & & & \\
\hline $\begin{array}{l}\text { 9. Aplicación a activos financieros y pasivos financieros } \\
\text { con posiciones compensadas en riesgos de mercado } 0 \\
\text { riesgo de crédito de la contraparte }\end{array}$ & & & \\
\hline 10. Valor razonable en el reconocimiento inicial & $\mathbf{1 0} \mathbf{( 7 1 , 4 3 \%}$ & $\mathbf{1} \mathbf{( 7 , 1 4 \% )}$ & $\mathbf{3} \mathbf{( 2 1 , 4 3 \% )}$ \\
\hline 11. Técnicas de valoración & $\checkmark$ & & \\
\hline 12. Datos usados en las técnicas de valoración & $\checkmark$ & & \\
\hline 13. Jerarquías de valor razonable & & & \\
\hline 14. Revelaciones & & & \\
\hline Total & & & \\
\hline
\end{tabular}

A partir de esta clasificación se llega a la conclusión que el $71,43 \%$ de las premisas que forman parte de la NIIF 13, se originan en los planteamientos expuestos por IASB en el borrador de discusión del 2006. No obstante algunas de ellas se limitan a su enunciación y se desarrollan y sustentan a lo largo del debido proceso. En consecuencia, el $28,57 \%$ restante hace referencia a las premisas que fueron replanteadas con respecto a las propuestas originales $(25 \%)$ y a las que surgieron en el proceso, en adición a lo inicialmente establecido en el borrador de discusión (75\%).

Se observa un porcentaje importante de propuestas iniciales de IASB que se incluyeron en la NIIF 13, lo que en este proyecto en particular puede obedecer al hecho de que la propuesta original tuvo como referente el SFAS 157 de los US-GAAP, dentro del proceso de convergencia entre IASB y FASB, logrando un nivel mayor de aceptación entre los diferentes participantes en el proceso. Respecto del $28,57 \%$, debe resaltarse su significancia evidenciando el objetivo que persigue el desarrollo del debido proceso en la emisión de las Normas Internacionales de Información Financiera. No obstante habrá quienes consideren que su impacto es insuficiente, un debido proceso no necesariamente implicará la transformación de las propuestas iniciales.

Este trabajo alienta a seguir realizando esta clase de análisis para otras normas sobre las cuales se tenga acceso a la información sobre su evolución, permitiendo, tanto el análisis de los planteamientos conceptuales y técnicos, como el análisis de los efectos del debido proceso.

4 Fuente: Elaboración propia. 


\section{Referencias}

Cairns, D., Massoudi, D., Taplin, R. \& Tarca, A. (2011) IFRS fair value measurement and accounting policy choice in the United Kingdom and Australia. En: The British Accounting Review, 43: 1-21.

Castellanos, H. (2009) El valor razonable y la calidad de la información financiera. En: Vision Gerencial, 9 (2): 269-282.

Financial Accounting Standards Board - FASB (2011) Accounting Standard Update No. 2011-04 Fair Value Measurement (Topic 820) Disponible en: http://www.fasb.org/cs/BlobServer?blobc $\mathrm{ol}=$ urldata\&blobtable $=$ MungoBlobs\&blobkey=id\&blobwhere $=1175822486936 \&$ blobheader $=$ application\%2Fpdf

G-20 (2009) Declaration on strengthening the financial system London, 2 April 2009-. Disponible en: http://www.g20.org/Documents/Fin_Deps_Fin_Reg_Annex_020409___1615_final.pdf

Georgiou, O. (2008) Gaining legitimacy: where has Fair Value Accounting come from? En: School of Accounting, Finance and Management. Disponible en: http://www.cardiff.ac.uk/ carbs/conferences/abfh2008/omiros.pdf

International Accounting Standards Board - IASB (2006) Discussion Paper: Fair Value Measurement. United Kingdom.

International Accounting Standards Board - IASB (2009a) Exposure Draft ED/5: Fair Value Measurement. United Kingdom.

International Accounting Standards Board - IASB (2009b) Basis for Conclusions. Exposure Draft ED/5: Fair Value Measurement. United Kingdom.

International Accounting Standards Board - IASB (2010) Discussion Paper: Extractive Activities. United Kingdom: April 2010. Disponible en:http://www.ifrs.org/NR/rdonlyres/735F0CFC-2F5043D3-B5A1-0D62EB5DDB99/0/DPExtractiveActivitiesApr10.pdf

International Accounting Standards Board - IASB (2011a) NIIF 13: Medición del Valor razonable. United Kingdom.

International Accounting Standards Board - IASB (2011b) Fundamentos de las Conclusiones. NIIF 13: Medición del Valor razonable. United Kingdom.

International Accounting Standards Board - IASB \& Financial Accounting Standards Board - FASB (2002) Norwlak Agreement. Disponible en: http://www.fasb.org/cs/BlobServer?blobcol=u rldata\&blobtable $=$ MungoBlobs\&blobkey $=i d \&$ blobwhere $=11$ 75819018817\&blobheader = application\%2Fpdf

International Accounting Standards Board - IASB \& Financial Accounting Standards Board - FASB (2006) A Roadmap for Convergence between IFRSs and US GAAP_-2006-2008 Memorandum of Understanding between the FASB and the IASB. Disponible en: http://uww.iasplus.com/pressrel/0602roadmapmou. pdf

Jacques, R. (2004) The Secret Past of Fair Value: Lessons from History Applied to the French Case. En: Accounting in Europe, 1(1): 95-107.

Navarro, A. \& Pérez, C. (2007) La repercusión del valor razonable de los bienes inmuebles en la utilidad de los estados financieros: una nota de investigación. En: Revista de Contabilidad-Spanish Accounting Review, 12 (1) Disponible: http://www.rc-sar.es/ verPdf.php?articleld $=190$

Novoa, A., Scarlata, J. \& Solé, J. (2009) Procyclicality and Fair Value Accounting. International Monetary Fund.

Patiño, A. (2009) El valor razonable en las inversiones de grupos económicos. En: Cuadernos de contabilidad, enero-junio 2009, 67. Disponible: http://www.javeriana.edu.co/fcea/cuadernos_contab/vol10_n_26/vol10_26_3.pdf

Sarbanes-Ōxley Act (2002) Disponible en: http://fl1.findlaw.com/ news.findlaw.com/cnn/docs/gwbush/sarbanesoxley072302.pdf

Security and Exchange Comission - SEC (2008) Report and Recommendations Pursuant to Section 133 of the Emergency Economic Stabilization Act of 2008: Study on Mark-To-Market Accounting. Disponible en:http://www.sec.gov/news/studies/2008/marktomarket123008.pdf

Silva, B. \& Azua, D. (2006) Avances sobre el concepto de valor razonable. En: CAPIV REVIEW, 4: 61-76.

Solomon, F. (1936) Revaluations of fixed assets, 1925-1934. En: National bureau of economic research, $N^{\circ} 62$ : 1-12.

Zeff, S. (2007) The SEC Rules Historical Cost Accounting: 1934 to the 1970s. Working paper, Rice University.

Zuñiga, F., Pacheco, L. \& Díaz, J. (2009) Convergencia contable: cambios profundos en la contabilidad chilena: activo fijo, un caso a considerar. En: Capic Review, 7. Disponible: http:// www.capic.cl/capic/images/vol7tema6.pdf 